\title{
Exploring and Practicing of Bilingual Teaching in Optional Geoscience Courses
}

\author{
Xiaohu Zhou ${ }^{1,2, a^{*}}$, Dong Zhao ${ }^{1, b}$ \\ ${ }^{1}$ Department of Geology, Northwest University, Xi'an, Shaanxi, China, 710069 \\ ${ }^{2}$ State Key Laboratory of Continental Dynamics, Northwest University, Xi'an, Shaanxi, China, 710069

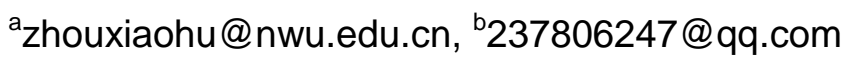

Keywords: Geoscience; Geology; Optional Course; Bilingual Teaching

\begin{abstract}
In this paper, the concept in bilingual classes evaluation system of earth science, features, functions, the theoretical basis for resolution are discussed on the basis of the necessity and feasibility of professional geoscience establishment and development of undergraduate bilingual teaching evaluation system. Through the research of the current domestic undergraduate geoscience bilingual teaching evaluation system and the using of dynamic management, people management and the main theoretical classification management, new ideas will be applied to evaluate the work of the bilingual class teachers. Taking the bilingual classes developing evaluation theory as a guide, we explored the evaluation index system of bilingual classes to promote the professional development of teachers for bilingual classes. On this basis, as well as the development of theory and science-based undergraduate bilingual teaching evaluation system a new teacher evaluation system,Bilingual dynamic evaluation of the Earth Science Division, was formed with the main purpose of guiding and motivating all teachers.
\end{abstract}

\section{Introduction}

Professional English communication skill level of college students is often lower than what they should be, which is a big obstacle for the development of our modern science,no doubt. We have been leaving far behind the India in the development of service-based outsourcing information technology and other parts because of the poor English and lacking of practical application skills of Chinese university graduates. This should sound the alarm for us beyond questions. Therefore, it is the priority for us to strengthen the bilingual education in the university of science and engineering. At present, a fascinating trend has appeared that bilingual education has been carried out in a number of universities and the theories and their utilization have been greatly developed.

The same problem exists in earth science teaching. Besides the Earth Sciences and related professional courses, a lot of electives are offered, which are mostly taught by Chinese. Few bilingual teaching is very unfavorable for the training and learning of students' English ability. Therefore, it is necessary to offer a few of bilingual teaching courses in earth science, and if the better effects were achieved, the mode of teaching methods could be promoted and popularized so that lay a good foundation for the training of high-quality talents.

\section{Effective ways to improve bilingual education}

The practice teaching in English. The essence of bilingual education is the coherence of teaching process. It is a good choice for us to alternatively use both English and Chinese to explain contents. However,it is unnecessary to artificially interrupted the process of teaching because this will greatly poison the teaching atmosphere and burden the students. On the one hand, the artificially interruption will make bilingual teaching just going through the motions, the called formalism. On the other hand, continuously switching between the two languages, students are easily distracted and more difficult to understand the concepts. The constant mixture will strengthen the already existing "Chinese English", which is contrary to the bilingual teaching. Furthermore, bilingual mixed explain will be a great test for 
the overall quality of teaching and teachers. Therefore, taught in English was adopted from the outset to guide students to understand the concepts so that students will be able to gradually adapt to the beginning of explaining in English and understanding the science content.

English teaching interaction. Teachers taught in English, and students answered questions. Although it is also a way of bilingual teaching, we believe that students should be able to express their English learning experience in order to truly improve the effect of bilingual teaching. Therefore, we require students to ask questions in English as much as possible. Of course, we do not exclude the after-school reading of Chinese literature, which could even be in English or comparative reading. Unlike English courses taught in English, the focus of teaching is still on professional knowledge. Teaching in English set a higher request to students for previewing the lessons and after-school review in order to adapt to the progress of class teaching,which will greatly improve the students' enthusiasm and initiative and in some extent contributed to the construction of undergraduate study style.

Comprehensive closed-book exam in English. In addition to the Chinese-English keywords translation, other kinds of questions, including terminologies, choices, drawings and quiz questions should be answered in English in each exam. Based on the practice of past two years, we found that the rate of exam did not change much with the changing of Chinese professors. The interesting phenomenon is that students get significantly higher scores in the test with the unchanged degree of difficulty. This shows that a kind of Power Learning is virtually formed in order to meet the requirements of the English exams.

The practice of bilingual teaching - A complete system of teaching practice in bilingual teaching is a very important part. To impel the integration of English teaching,all the indoor and outdoor lectures and internships were taught in English. Internship achievements in English were also required, including internship reports, diaries, field record books because students already grasped the basic English skills after completing a series of basic geoscience courses and internship arrangements. According to our experience in the field, students are fully able to adapt to the whole English teaching and learning environment and complete the writing of English report in the interior finishing. In addition, another important harvest in the field practice is the great improvement of students' oral proficiency.Students have learned the assembly of "elements or parts of language"through repeated field practices. In fact, their English vocabularies were rich enough to express themselves, what they need is a suitable environment. In the wild, they are more conscious or even more courage to express themselves because of the beautiful landscapes, plenty of geological phenomena and less binding of tense atmosphere. Of course, there are some problems. The main problem is the teachers. Teachers are the key issues and soul of bilingual teaching. Due to the impact of workload and teaching establishment, the number of teachers is strictly limited.It is usually not more than one speaker teachers, together with auxiliary teaching staffs, and about twenty-three around. Meanwhile, out of reasonable causes, we do not have the ability to introduce foreign teachers. These make our exploration more limited. It should also present a widespread problem that exist in geoscience foundation courses that offered in a non Geological institutions. Geology courses, such as general geology, mineral petrology and structural geology, have different levels of contribution in civil engineering, surveying, urban planning, water, geography, and materials, and even archeology and other disciplines. Therefore, the above problem is of universal and representative and further explorations are needed to solve this problem.

The helpful Bilingual Glossary. Beginners are not familiar with specialized vocabularies and this will inevitably result in the difficulty in correctly understanding the contents. To solve this problem, you can use the approach of writing and teaching or offer a teaching materials that supporting bilingual vocabularies. For example, during the bilingual teaching process of "Structural Geology", you can write "bilingual tectonics commonly used terms"; you can also more commonly use the book of "Foundations of Structural Geology"that supporting the" English-Chinese Selected structural geology specialized vocabulary. " The book was supplementary revised in 2004 and was offered to students for internal use and reference. "Metamorphic Petrology" and "general geology" of bilingual edition are 
also written for bilingual education. These specialized vocabulary are welcomed by the students. The teaching survey of Structural Geology showed that most students thought that bilingual glossary were useful.

\section{Useful suggestions to bilingual education}

Students generally did not grasp enough professional English vocabularies and lacked the capacity of the international communication. After graduate school is still small for professional English communication. The bilingual education of "Metamorphic geology",classroom English quizzes, homework, English lab reports, field observations, and repeated training have improved the students' English listening, speaking, reading and writing skills in English and the quality of academic communication and the situation has changed radically above. Students of base classes have been able to actively participate in the academic report of foreign experts and discuss academic issues with foreign experts by them own. Meanwhile,students can be more smoothly read the professional foreign periodicals and track geology forefront of scientific research.Therefore,the implementation of bilingual teaching will accelerate the pace of cultivation of innovative talents. For example, a number of papers composed by science students in class have been published on the core journals,some even on the country's top journal "science" in English.

The foreign advanced teaching concepts and teaching methods should be introduced to promote rock teaching reform. "metamorphic geology" bilingual teaching has become a successful trial for the advancing of teaching concepts methods.

\section{Summary}

Currently, while promoting bilingual education, we are also meeting some difficulties as follows: 1 . The short of high-level bilingual education teachers. Just at the beginning of the construction of the science base, bilingual education had become a rigid requirement and a significant assessment indicator of Ministry of Education. Some general teacher could only participate in bilingual education actively because of the lacking of high grade bilingual teachers. However, seven, eight years later, our bilingual teachers of English teaching is still lacking. A few of experts are studying abroad and the elites just served the bilingual education as a task for limited time. Bilingual education did not change radically. Therefore, the schools and faculties should step up training bilingual education based teachers in the future training process. 2.It is still a difficult task to encourage a high level of investment in bilingual education. Current teaching load calculation did not truly reflect the pay of bilingual teaching. Some universities will calculate bilingual teaching hours at the rate of 1: 1.5 because of the low rate of teaching investment returns compared with the workload of bilingual teaching, which leads to the less and less bilingual education teachers. At present, our school personnel system reform should involve teaching task. If we continue to promote bilingual education, bilingual education should be taken as a special treat when considering the task of teaching.

\section{Acknowledgements}

The work was financially supported by Undergraduate teaching quality and reform project Foundation of Northwest University (JX13029), Program for Changjiang Scholars and Innovative Research Team in University (IRT1281), National Natural Science Foundation for innovative research groups (D02) and the Natural Science Foundation of Shaanxi Province (2013JM5008).

\section{References}

[1] Zeng Zuoxun, Ouyang Jianping, Yang Kunguang, etc. Practice and Experience of bilingual teaching in geology science base [J]. Chinese Geological Education. (2) 2004,30-32. 
[2] Ren Liangyu, Li Jing, Liu Hai-hong, Zhou Jun. Bilingual teaching Problems and Countermeasures[J]. Advanced Agricultural Education. (3) 2004,78-79.

[3] Ha Jianping, Hu Xiang. Bilingual teaching in Nanchang Institute[J]. Aeronautical Technology (Social Sciences). (1)2006, 87-90.

[4] Sang Longkang, Jinhua, Thinking to new Teaching model[J]. China University of Geosciences (Social Sciences). (4)2001, 57-60.

[5] Wang Xudong. "bilingual education" in China,Shanghai International Studies University, [J]. China Education Daily, (4) 2000.

[6] Zhang Yao. Srudy of strengthening English teaching practicality to improve students' English comprehensive ability[J]. China Higher Education Research, (8) 2002.

[7] Wang Fengyu. Expansion and cautions of Bilingual Teaching[J]. Shenyang Normal University (Social Sciences). (6)2006.

[8] Zhang Guangjun, Wang Yufeng, Zhou Yunhong. Review of Curriculum Evaluation Model[J]. High school journal. 21 (4) 2006, 18-20.

[9] Liu Yao. Study of development process of curriculum evaluation model [J]. Contemporary educational theory and practice. 3 (12)2011, 26-29.

[10] Liu Peipei. Several typical modes of curriculum evaluation[J]. Hubei Normal University, 28 (3)2011, 117-119.

[11] Jiang Lijing. Evaluation model analysis of values curriculum[J]. Guangzhou Radio and Television University. (6)2005, 42-45.

[12] J.P. Wright. The concept of curriculum evaluation[J]. Foreign primary and secondary education. (5) 1997.

[13] Chen Xia. Curriculum theory[M]. Beijing: People's Education Press, 1989.

[14] Ping Shengyao. Curriculum evaluation and critical analysis[J]. Education Research. (9)1996, 54-56. 